\title{
Matej Župančič
}

Krožna cesta 8, SI-6000 Koper

matej.zupancic@guest.arnes.si

\section{Človek volku volk (o odnosih človeka in volka v Historia Langobardorum Pavla Diakona)}

\author{
Izvorni znanstveni rad | Original scientific paper \\ UDK 94(363.5) \\ Primljeno: 27. I. 2012.
}

\section{Izvleček}

Avtor obravnava pobeg Langobarda Lopichisa iz avarsko-slovanskega ujetništva v prvi polovici 7. stoletja, kot ga opisuje kronist Pavel Diakon v drugi polovici 8. stoletja. Avtor domneva, da so Langobardi in Avari s Slovani sledili "alternativni" poti, kot jo je začrtal S. Ciglenečki. Opis bega je vrinjen v Zgodovino Langobardov, saj vsebuje cel niz dogodkov, ki jih je možno interpretirati le kot osebnostni razvoj begunca ob njegovi iniciaciji. Avtor domneva, da je begunec na povratku izbral Langobardom znano "alternativno" pot iz Panonije čez Dolenjsko in Notranjsko v Furlanijo. Segmente te poti omenja že Strabon, v poznem srednjem veku pa je služila za pregon živine iz Panonije proti Trstu. Avtor omenja tudi jezikovni stik begunca $s$ Slovanko in s tem posredno pritrjuje tezi M. Levaka o slovanski naselitvi Istre že $\mathrm{v}$ 1. polovici 7. stoletja.

\section{Sintesi}

L'autore prende in esame l'episodio della fuga del Longobardo Lopichis dalla cattività avaro-slava, risalente alla prima metà del VII secolo e descritta dal cronista Paolo Diacono nella seconda metà dell'VIII secolo. L'autore presuppone che i Longobardi, come gli Avari e gli Slavi, seguivano un percorso "alternativo" tracciato da S. Ciglenečki. La descrizione della fuga è stata inserita nella Storia dei Longobardi e contiene tutta una serie di vicende che è possibile interpretare soltanto come uno sviluppo personale del fuggiasco al momento della sua iniziazione. L'autore presuppone che il fuggiasco al suo ritorno scelse di seguire il percorso "alternativo", conosciuto dai Longobardi, che portava dalla Pannonia, attraverso la Bassa Carniola e la Carniola interna, in Friuli. Dei segmenti di tale percorso erano già stati menzionati da Strabone, mentre nel basso medioevo era stato usato per condurre il bestiame dalla Pannonia verso Trieste. L'autore si sofferma anche sull'episodio del 
contatto linguistico del fuggiasco con una Slava, il che indirettamente conferma la tesi di M. Levak sull'insediamento slavo dell'Istria già nella prima metà del VII secolo.

Ključne besede: Slovani, Istra, Langobardi, alternativna pot, 7. stol., Historia Langobardorum, Lopichis, volk, Paulus Diaconus, S. Ciglenečki, M. Levak

Parole chiave: Slavi, Istria, Longobardi, percorso alternativo, VII secolo, Historia Langobardorum, Lopichis, lupo, Paolo Diacono, S. Ciglenečki, M. Levak

Langobardski kronist Pavel Diakon v opisu bega svojega pradeda Lopichisa iz ujetništva v Panoniji proti domu v Furlaniji oziroma v Čedadu omenja volka-spremljevalca, nekakšnega psihopompa. Pa tudi več drugih dogodkov, opisanih v kronistovi pripovedi, zajema vsebine, ki so na meji resničnosti in sanj ter močno odstopajo od običajnega zgodovinopisja. Lopichisova zgodba se je dogajala v prvi polovici 7., langobardski kronist pa jo je zapisal v drugi polovici 8. stoletja. Ustna tradicija, ki jo je kronist zapisal, bo obravnavana v smislu interakcije med "običajno" realnostjo in duhovnim dozorevanjem begunca, ki pa je prav tako "realno". Izbor dogodkov, za katere izvemo, je seveda stvar primarnega pripovedovalca ter prenašalcev skozi 150 let vse do kronista Pavla. Sama zgodba Lopichisa ne spada v "véliko" zgodovino Langobardov, pač pa v družinsko in jo kot tako obravnavamo. Kot možno realnost jemljemo tudi alternativno (južno) pot selitve Langobardov čez današnjo Slovenijo in tudi beg na zahod po tej poti. Iz rahlega tkiva historičnih, geografskih in lingvističnih podatkov do določene mere podkrepimo zgodnjo naselitev Slovanov v Istri.

V prvi polovici 7. stoletja se je v današnji južni Sloveniji, kot domnevamo, zvrstilo kar nekaj dogodkov, ki so z našega stališča nenavadni in onkraj resničnosti, a jih bomo skušali osvetliti in povezati. Zato se je primerno opreti na originalni del Diakonovega teksta (glej Prilogo na koncu), kolikor se nanaša na Lopichisov pobeg in povratek. Večino podatkov povzemam po slovenski izdaji Historiae Langobardorum Pavla Diakona, ${ }^{1}$ kljub temu, da je novejša hrvaška izdaja² mnogo bogatejša s historičnimi opombami in v mnogočem dopolnjuje slovensko. Žal tudi ta novejša ne upošteva "alternativne" poti selitve.

1 Pavel Diakon, Zgodovina Langobardov, prevedli Fran Bradač, Bogo Grafenauer in Kajetan Gantar, opombe napisala Bogo Grafenauer in Kajetan Gantar, Maribor 1988.

2 Paulus Diaconus, Historia Langobardorum / Pavao Đakon, Povijest Langobarda, preveli Robert Šćerbe i Hrvoje Šugar, povijesni komentar priredili Tomislav Galović, Ivo Goldstein i Hrvoje Gračanin, povijesne studije Tomislav Galović i Hrvoje Gračanin, Zagreb 2010. 
Začetek zgodbe mladega Lopichisa, kronistovega prednika, Bogo Grafenauer postavlja v leto 610, ko so Avari skupaj s Slovani oropali Čedad ter ujete ženske in otroke, med njimi tudi Lopichisa in njegove štiri bratce, odpeljali v ujetništvo v Panonijo, medtem ko so moške in Romildo, soprogo furlanskega vojvode Gisulfa, na poti pobili na kraju, imenovanem campus sacer. Domnevamo, da so otroci in ženske bili priče temu poboju. Od preživelih se je v Furlanijo vrnil le že odrasli Lopichis sam, verjetno kmalu po letu 640, kot sklepa Grafenauer glede na tedaj veljaven pravni predpis, ko Lopichis po preteku 30 let očetovega zapuščenega doma ni več mogel dobiti nazaj, saj si ga je medtem v dobri veri priposestvoval nekdo drug. Ob povratku je bil Lopichis v polni moški moči, saj je nemudoma odstranil ruševine rojstne hiše (ki očitno ni bila očetova), jo nato obnovil in si poiskal soprogo. Omenjena kronologija je nekoliko šibka. ${ }^{3}$

Že tako nestvarni zgodbi bomo dodali še našo domnevo, od kod in približno po kateri poti povratnik beži proti Čedadu. Kot izhodišče pobega ${ }^{4}$ smo ne popolnoma naključno izbrali okolico Siska v jugozahodni Panoniji; pot je begunca od tod vodila skozi današnjo južno Slovenijo, delno po alternativni poti $^{5}$ čez Dolenjsko in Bloke, južno od Razdrtega po Krasu v spodnjo Vipavsko dolino in dalje proti Čedadu. V bistvu je to stranska in “alternativna” pot, kot jo opisuje Slavko Ciglenečki. ${ }^{6}$ Pot je bila nedvomno že bolj opuščena kot ob domnevni uporabi 1. 610 ali celo spomladi 1. 568. Ko bi bil bežal po nekdaj glavni itinerarski cesti (nekako Poetovio-Emona-Aquileia), bi ga zasledovalci na konjih hitro došlì. Hkrati je srečanje z volkom, bodisi realnim bodisi imaginarnim, na stranski poti bolj verjetno kot ob

3 Maurizio Levak mi ljubeznivo pripominja, da se kronologija ne ujema, saj je Lopichisov oče živel v Italiji le nekaj let in je zapustil pet sinov, ki so bili 1.610 še nedorasli. Seveda se strinjam z njim, vendar poudarjam, da je zgodba o Lopichisu vrinek v Historio Langobardorum, in je napisana po družinski zgodbi, kjer kronologija ne igra najvažnejše vloge. Levak tudi dodaja, da je morda Lopichisov oče prišel v Italijo po 1. 568. Menim, da v tem primeru kronist tako dejstvo zamolči, saj je prihod v Italijo na Veliko noč dramatičen in za družinsko zgodbo nek separaten prihod ne bi bil zanimiv. Končno pa bi morda ne veljala Grafenauerjeva kronologija. Levakove pripombe uporabljam ali navajam na več mestih in se mu za pozorno branje zahvaljujem.

4. Na nekatere možne interpretacije teksta me je v razgovoru ljubeznivo opozoril zgodovinar Samo Pahor. Izbrano mesto prestajanja ujetništva je nekako najbolj prikladno kot izhodišče za beg; vsekakor je bilo pod avarsko in slovansko kontrolo.

5 Slavko Ciglenečki, "Potek alternativne ceste Siscija - Akvileja na prostoru zahodne Dolenjske in Notranjske v času 4. do 6. stoletja. Preliminarno poročilo o raziskovanjih Korinjskega hriba in rekognosciranjih zahodne Dolenjske" (v nadaljevanju: "Potek alternativne ceste Siscija - Akvileja“), Arheološki vestnik, 36, $1985,255-284$.

6 Ibidem; idem, "Poznoantično Posočje in problemi langobardske obrambe Italije”, Goriški letnik, 27, 2000, 51-66; idem, "Romani e Langobardi in Slovenia nel VI secolo", Paolo Diacono e il Friuli altomedievale (secc. VI-X), atti del XIV Congresso intern. di studi sull'Alto Medioevo, Cividale del Friuli, Bottenicco di Moimacco 24-29 sett. 1999, Spoleto 2001, 179-200. 
glavni, čeprav tudi že zamirajoči, prometnici. Ker je odraščal v ujetništvu, je za alternativno pot lahko zvedel od starejših in modrih Langobardk, ki so preživljale ujetništvo z njim. V ujetništvu je imel tudi priložnost, da se je priučil slovanščine, ki jo je pozneje potreboval za sporazumevanje na begu. Ni odveč omeniti, da je tudi potovanje v ujetništvo potekalo verjetno po isti poti (le v nasprotni smeri), že glede na celo vrsto za našo interpretacijo pomenljivih dogodkov, ki so se pripetili na poti v ujetništvo in tudi na Lopichisovem povratku. Avari in Slovani so se z ujetniki iz Furlanije vračali sicer po najugodnejši poti proti Sisku in to je lahko, predpostavljamo, bila “alternativna” pot Langobardov iz leta 568.

Na poti je Lopichis naletel le na eno samo naselbino, medtem ko bi bile na poti čez Koroško, Štajersko ali zgornjo Kranjsko take naselbine pogostejše. ${ }^{7}$ Pot po južnejši smeri, na koncu mimo Razdrtega po Krasu in v Vipavsko dolino nekje pri Batujah - do Batuj so namreč ozemlje kontrolirali Langobardi $^{8}$ - je do Čedada dolga vsaj $240 \mathrm{~km}$. Če odštejemo neznano število dni Lopichisovega okrevanja pri Slovanki, je najprej potoval "nekaj dni”, potem pa zopet “nekaj dni”. Zadnji del poti iz Vipavske doline do Čedada je bil v vsakem pogledu manj zahteven in je bilo napredovanje po cesti hitrejše. Grob izračun, ob predpostavki, da je bil postanek pri Slovanki nekje na sredini poti, in ocena, da pomeni "nekaj dni” 5 dni, nam dasta deset dni hoje po 23 do $25 \mathrm{~km}$ na dan, kar je sprejemljivo. Del poti se ujema s smermi, kot so jih ugotavljali Strabon, Ciglenečki in Ferdo Gestrin. Smer v celoti, oziroma po nekaterih odsekih, je v zgodovini tega ozemlja torej večkrat omenjena oziroma umeščena v prostor: v zvezi s to smerjo grški zemljepisec Strabon omenja "prelaz Ocra". Menimo, da bi bilo potrebno ta prelaz kot prehod umestiti širše, vključujoč še pred kratkim močno vodnato področje Notranjske med Nanosom in Snežnikom. Strabon nadaljevanje poti proti vzhodu vidi v dveh možnih smereh, in sicer od Ocre proti Nauportusu in dalje ter od Ocre proti Lugeonu in dalje proti reki Corcoras (Krka). Le maloštevilni domnevajo, da bi ime Corcoras označevalo Ljubljanico: v tem primeru bi bilo seveda odveč naše dokazovanje “dolenjske poti po Strabonu” čez

7 Lopichis se je vsekakor izogibal naseljenim krajem, šele stiska in lakota sta ga prignali do osamljenega bivališča s starko. M. Levak me je prijazno opozoril, da Prokopij piše, da so Slovani prebivali v hišah, ki so bile med seboj oddaljene. Opažanje se nekako ujema z ugotovitvami M. Guština za zgodnjo slovansko poselitev v Prekmurju (Mitja Guštin [ur.], Zgodnji Slovani: zgodnjesrednjeveška lončenina na obrobju vzhodnih Alp = Die frühen Slawen: frühmittelalterliche Keramik am Rand der Ostalpen, Ljubljana 2002) v SV Sloveniji.

8 Drago Svoljšak - Timotej Knific, "Vipavska dolina. Zgodnjesrednjeveška najdišča”, Situla, 17, Ljubljana Nova Gorica 1976 (1977). 
Bloke. Smer proti Krki namreč povezujemo s starejšimi viri, ki nakazujejo pot proti železnodobnim naselbinskim središčem Dolenjske ob Krki, morda proti Stični in / ali kompleksu Dolenjske Toplice / Novo mesto, saj podatki v Strabonovi 7. knjigi odsevajo še halštatskodobne razmere. ${ }^{9}$ Prehod med Razdrtim, Cerkniškim jezerom in Ložem je širok in dopušča več variant. Posebej imamo pred očmi dve dosti poznejši obdobji "alternativne poti” iz doline Krke: najprej alternativno pot v 6. st., ki naj bi jo tudi uporabili Langobardi na pohodu v Italijo leta $568,{ }^{10}$ in srednjeveško pot za pregon govejih čred iz Panonije proti Trstu ${ }^{11}$. Gestrin poleg drugih srednjeveških poti za trgovanje z živino omenja tudi pot od Zagreba po dolini rek Save in Krke navzgor do njenega izvira oziroma do vasi Krka, nato na Lož oziroma Cerknico in proti Postojni. Pri omenjeni varianti skozi Lož bi se skušali navezati tudi na smer, ki jo je predlagal Alberto Puschi za potek rimske ceste (Stari trg / Lož, Dane, Stare ogence, Parje, Velika Pristava, Stara Sušica, Buje in po dolini reke Reke) do Škocjana, ${ }^{12}$ kjer se spoji s Strabonovo potjo iz Trsta proti Ocri. Razumljivo je, da govorimo bolj o smereh kot zgrajenih cestah, kajti v 1. polovici 7. stoletja je bila verjetno celo rimska itinerarska pot iz Ogleja skozi Emono do Ptuja za beg slabo uporabna.

Dejstvo, ki ga opisuje P. Diakon in zanima nas, je Lopichisov beg po goratem in gozdnatem ozemlju, kjer begunec pravzaprav ne ve ne kod ne kam, a vendar najde smer proti zahodu. V zgodbo so vpleteni dogodki, ki niso običajni, a pripomorejo $k$ srečni vrnitvi Lopichisa domov: v njem se najprej prebudi želja po vrnitvi (A1: "captivitatis iugum abicere statuit et ad Italiam”). Štiri brate pusti v sužnosti, a jim pripovedovalec ne navede niti imen. Za pot se je, kljub nenadni odločitvi zanjo, pripravil, saj si je vzel tul s puščicami, lok (nedvomno avarskega refleksnega) in nekaj živeža (A2: "adgressus fugam adripuisset, faretram tantum et arcum et aliquantulum cibi propter viaticum gerens”). Med tavanjem sreča volka in se prepusti njegovemu vodstvu (B1: "nesciretque omnino quo pergeret, ei lupus adveniens comes itineris et ductor effectus est”). Ko se mu je oglasila nepremagljiva

9 Marjeta Šašel Kos, "Nauportus: antični literarni in epigrafski viri", v: Jana Horvat (ur.), Nauportus (Vrhnika), Ljubljana 1990, 17-33.

10 Ciglenečki, "Potek alternativne ceste Siscija - Akvileja"; idem, "Poznoantično Posočje in problemi langobardske obrambe Italije", 51-66; idem, "Romani e Longobardi in Slovenia nel VI secolo", v: Paolo Diacono e il Friuli altomedievale (secc. VI-X), 179-200.

11 Ferdo Gestrin, Slovenske dežele in zgodnji kapitalizem, Ljubljana 1991, 178-180.

12 Alberto Puschi, "I valli romani delle Alpi Giulie”, Archeografo triestino, 24, suppl., 1902, 143. 
lakota, se odloči, da bo volka ubil in pojedel ${ }^{13}$ (B2: "iam fame tabefactus defecisset, tetendit arcum suum et eundem lupum, ut eum in cibum sumere possit, sagitta interficere voluit”). A volk pravi čas odskoči in mu izgine izpred oči (B3: "Sed lupus idem ictum ferientis praecavens, sic ab eius visione elapsus est”). S tem prepreči uboj-samomor. Bolj mrtev kot živ od utrujenosti in lakote zaspi in v sanjah (C1: "obdormivit; viditque quendam virum in somnis talia sibi verba dicentem: 'Surge! Quid dormis?’”)14 izve, v katero smer naj beži - čeprav je smer proti zahodu (Italiji) izbral že na začetku (C2: "Arripe viam in hanc partem contra quam pedes tenes; illac etenim est Italia, ad quam tendis”). Kaže, da se s tem stvari postavijo na pravo mesto, Lopichis pa na svoje noge. Sanje so se dogodile verjetno v drugem delu noči, ko se človek za kratek čas prebudi in "stvari pridejo na pravo mesto". ${ }^{15}$ Na tem mestu se je dogodil v snu kritični preobrat, ker od sedaj se dogodki odvijajo v "realnem” svetu in Lopichis prične delovati samostojno, v skladu z navodili moške postave iz sanj, a tudi tega, k čemer je že prej usmerjal svoja hotenja. Po tem dogodku Lopichis prispe do slovanskega naselja (končno ljudje!) (D1: “ad habitaculum hominum pervenit. Erat enim Sclavorum habitatio in illis locis”), kjer ga izmučenega skrivaj neguje starejša Slovanka (D2: "Quem cum una mulier iam vetula vidisset, statim intellexit, eum fugitivum esse et famis penuria laborare. Ducta autem misericordia super eum, abscondit eum in domo sua et secreto paulatim ei victum ministravit, ne, si ei usque ad saturitatem alimoniam praeberet, eius vitam funditus extingueret”). Tudi Slovanka mu pove (se je slovanskega jezika naučil že v ujetništvu ali, manj verjetno, se je ona naučila langobardščine?; strinjam se $\mathrm{z}$ Mauriziom Levakom, ${ }^{16}$ da kronist ne čuti potrebe objasniti situacijo, saj mu je bilo povsem razumljivo, da furlanski Langobard razume ta jezik) za pot proti domu (D3: "Denique sic conpetenter ei pastum praebuit, quo-

13 M. Levak je posredoval odlomek iz germanske književnosti: Edda, Pesem o Sigurdu (9. st.): "Jedni pekoše vuka, drugi sjekoše zmiju, treći dadoše Guttormu vučjeg mesa, prije nego što zločincima pođe za rukom da se dokopaju mudroga čovjeka." (Nevenka Košutić-Brozović, Čitanka iz stranih književnosti, I. dio, Od starog vijeka do klasicizma, Zagreb 1995, 212), kar se dobro sklada z Lopichisovim strelom na volka in poznejšim srečanjem z modrim moškim v snu.

14 Začetek (seveda v množini) kot Luka 22:46. Za pripombo se zahvaljujem V. Prozorovu. Prav tako začetek v Hieronimovem komentarju h Knjigi 13 o Isiahu: "Et cum psalmista loquere: Exsurge, ut quid dormis, Domine?" V Psalmih pa 44:24: "Evigila, quare obdormis, Domine? / Exsurge et ne repellas in finem." Za obe pripombi se zahvaljujem J. Dillonu. Obakrat pa manjka vsebina o nogah.

15 "Even shepherds and old country-folk, who are the deepest read in these arcana, have not a guess as to the means or purpose of this nightly resurrection. Towards two in the morning they declare the thing takes place; and neither know or inquire further." A. Roger Ekirch, "Sleep We Have Lost: Pre-industrial Slumber in the British Isles", The American Historical Review, 106, 2, 2001.

16 Sugestija M. Levaka v razgovoru po objavi mojega prikaza knjige Slovani vojvode Ivana (Matej Župančič, "Slovani vojvode Ivana", Zgodovinski časopis, 62/1-2, 2009, 216-221). 
usque ipse recuperatus vires accipere potuisset. Cumque eum iam validum ad iter faciendum vidisset, datis ei cibariis, ad quam partem tendere deberet, admonuit”). To je bil predzadnji pravljični dogodek, povezan z begunčevim povratkom. Zadnji tak dogodek se po nekaj dneh dogodi že v Čedadu. Tam rojstno hišo, že ruševino, očisti trnja in robide ter pri tem odkrije velik "mali jesen" (Fraxinus ornus), ${ }^{17}$ na katerega obesi svoj tulec s puščicami in lok (E: "ad domum in qua ortus fuerat pervenit; quae ita deserta erat, ut non solum tectum non haberet, sed etiam rubis et sentibus plena esset. Quibus ille succisis intra eosdem parietes vastam hornum repperiens, in ea suam faretram suspendit”). Trnje z robido je splošen izraz, kronist pa posebej pove, da je Lopichis sredi ruševine naletel na veliko drevo, jesen - hornus, po mnenju mnogih sveto drevo Germanov (iz poznejših virov) gggdrasil.

Dogajanja v zvezi z odločitvijo za pobeg z lokom, kot tudi beg z volkom in strel nanj ter napotki moškega v sanjah, pogovori z lečečo starko, ki pokaže pot naprej, obešanje orožja na drevo in čiščenje okoli drevesa v domači hiši so v osnovi skoraj legendarna in smo jih kot taka skušali prikazati. Zgodba v celoti in posamezni deli v njej so v bistvu iniciacija mladega moškega, še posebej srečanje z volkom in bivanje pri starejši ženski-Slovanki. Ob epizodi z volkom-senco se vrine tudi imenska dvojnost, lupus - Lopichis, kar je že bilo poudarjeno. ${ }^{18}$ Domnevamo, da je prav navedenih pet (A-E) dogodkov Pavla Diakona navedlo, da je begunčevo štorijo vključil v Historio. Da si je Lopichis zgradil hišo in poiskal žensko, s katero sta začela novo linijo potomcev vse do pisca Zgodovine, zveni le kot običajen zaključek pravljice in spada v realnost, tako družinsko kot plemensko. V osmem stoletju so torej med Langobardi, celo v Čedadu, še vedno prisotni poganski prežitki. V družinskem ustnem izročilu-pripovedi ${ }^{19}$ je skrita

17 Hornus = klas. latinski ornus, "mountain ash tree”, veliki jesen, kot se večkrat domneva. Vendar mi Robert Brus sporoča (e-pošta: 10. 9. 2009), da v srednjeveški latinščini Paula Diacona izraz hornum prevajajo kot "mountain ash", kar ni veliki jesen, pač pa je danes v Evropi izraz za jerebiko (Sorbus aucuparia). Ta spada med rožnice. Načelno bi v Čedadu pri hiši lahko rasla tudi jerebika, saj je gorska vrsta, ki je je že takoj v hribih nad Čedadom dovolj; poleg tega je skromen pionir, ki bi se lahko v ruševinah dobro znašel in verjetno še hitreje rasel kot mali jesen. Kljub temu je dr. Brus prepričan, da je v tekstu vendarle mišljen mali jesen (Fraxinus ornus), ki ga je tam dosti tudi še danes. Poleg tega pa so še v začetku 20. st. z izrazom mountain ash označevali mali jesen. Mali jesen je do 15 (20) $\mathrm{m}$ visoko in do 0,5 $\mathrm{m}$ debelo listopadno drevo $\mathrm{s}$ široko, košato, močno razraščeno krošnjo in kratkim, pogosto skrivenčenim deblom s sivo in gladko skorjo, ki v manjše ploščice razpoka šele pri starih drevesih.

18 Nicoletta Francovich Onesti, "L’incontro fra le culture latina e germanica nell'Italia longobarda alla luce del'antroponimia”, v: Dieter Hägermann - Wolfgang Haubrichs - Jörg Jarnut (ur.), Akkulturation. Probleme einer germanisch-romanischen Kultursynthese in Spätantike und frühen Mittelalter, Berlin - New York 2004, 208.

19 Otto Gschwantler, "Formen langobardischer mündlicher Überlieferung", Jahrbuch für internationale Germanistik, 11, 1, 1979, 81. 
kronika navadne in ne vladarske družine, pripovedovana živo, ki na vsak način danes še ni dovolj izkoriščena. Tako beremo zgodbo v Zgodbi, notranjo zgodbo begunca Lopichisa, Diakonovega prastarega očeta, v okvirni Zgodbi - Historii Langobardorum P. Diakona. Otto Gschwantler poudarja, da družinske zgodbe P. Diakon ne povzema po pisanih virih. ${ }^{20} \mathrm{~A}$ zgodba in Zgodba imata povezave, pravzaprav zrcaljenja: Romilda, Lopichisova odločitev za beg, izjava Pavla Diakona, da imen štirih Lopichisovih bratov ne pozna, in končno, povratnik je osnoval linijo potomcev, ki se izteče v kronista obeh zgodb.

Avtorji, ki obravnavajo dogodke v zvezi z Lopichisovim begom, po pravilu izberejo le po en motiv, pač glede na potrebo. Vlogo volka v zgodbi omenja Walter Pohl v zvezi z motivi vzhodnih stepskih ljudstev, v prvi vrsti Avarov. ${ }^{21}$ Florin Curta srečanje s starko razlaga v luči odnosa Langobardov do Slovanov, ki naj bi bil pozitiven, v nasprotju z njihovim odnosom do Avarov (pustošenje Furlanije, odnos med Romildo in kakanom, poboj moških ujetnikov itd.), ki naj bi negativen. ${ }^{22}$ Mnenje Curte je sicer zanimivo, a obe strani medalje nista uravnoteženi: na eni strani prijazen odnos begunca rekonvalescenta in starejše Slovanke, na drugi pa izdaja in poboj, posmehovanje Romildi, njena kruta usoda, z zlorabo po navidezni poroki, ${ }^{23}$ in natikanje na kol itd. Historično zlo je prisotno na obeh antagonističnih straneh (avarski in langobardski). Glede drevesa - jesena, v našem primeru malega jesena - omenjajo, da bi bilo lahko to sveto drevo Germanov, medtem ko bi mi poudarili odložitev orožja na drevo kot tropaeum ob zaključku potovanja.

Pogled v potek notranje zgodbe pokaže junakovo postopno metamorfozo in hkrati iniciacijo. Odločitve so se dogajale v njegovi notranjosti kot tudi skozi izkustva, kjer pa že spet moramo prav njemu samemu pripisati zapovrstne levitve. Kot ujetnik, nekje v Panoniji, vendar sorazmerno blizu Furlanije, se po dolgih letih odloči, da bo zapustil svoje štiri brate. Sam se je s tem sklepom izvil iz anonimnosti. Prisvojil si je lok - ta bo v zgodbi pomemben še dvakrat - in od gospodarjev pridobil tudi osnovno znanje slovanskega jezika, od sojetnic Langobardk pa približno predstavo o poti

20 Idem, 82.

21 Walter Pohl, Die Awaren: ein Steppenvolk in Mitteleuropa 567-822 n. Chr., München 1988, 192-193. Pohl poleg volka omenja tudi lok, ki si ga je vzel begunec, in ga pripisuje avarski tradiciji. Idem, 193.

22 Florin Curta, "Slavs in Fredegar and Paul the Deacon: medieval gens or »scourge of God«?”, Early medieval Europe, 6/2, 1997, 160.

23 Romilda je doživela poročno noč z avarskim kakanom, a ta jo je takoj prepustil svojim 12 poveljnikom $\mathrm{v}$ kolektivno zlorabo, nato pa jo je dal natakniti na kol in se ob tem besedno izživljal. Ob grozljivem dogajanju zaslutimo tudi blasfemijo. 
proti Italiji. Njegova samotna in utrudljiva pot po nenaseljeni hriboviti in gozdnati pokrajini se spreminja v blodnje, vendar v določenem smislu rešilne blodnje, saj ga volk-vodnik začne spremljati kot senca. Morda pa je bil Lopichis sam senca volku. Lakota naj bi ga bila prisilila, da si je zaželel volčjega mesa, a volk kanibalizma ni dopustil. Puščica je zgrešila, volk je izginil, begunec pa je ostal popolnoma sam, lačen in izčrpan. Od utrujenosti je omahnil v sanje, v katerih ga je nagovorila moška postava in mu poudarila, da njegove noge že vedo za pravo pot proti domu. Srečanje z moško postavo v sanjah, ki Lopichisu dokončno in imperativno izoblikuje usodo, spominja na srečanje danskega kraljeviča Hamleta $\mathrm{z}$ duhom umorjenega kralja Hamleta, njegovega očeta. Tudi mladi Hamlet je od prikazni-očeta izvedel le to, kar je bil že vedel. Po srečanju z moško postavo v sanjah se je tavajoči prizemljil in sledil svojima nogama. Očitno so se stvari v snu postavile na svoje mesto. Kmalu ga je vzela pod streho Slovanka in ga skrbno negovala in potem napotila proti domu. Lopichis je torej srečal vse, kar je bil izgubil: očeta, mater in cilj pred sabo. Po prihodu domov zgodba brez zapletov steče v srečen konec: dom očisti trnja in s tem osvobodi drevo, na katero lahko obesi lok, obnovi hišo ter si izbere soprogo, in čez stoletje in pol v družinsko zgodbo vstopi pravnuk, kronist Pavel Diakon.

Vloga volka, ki vodi in skorajda nadzira begunca, je dokaj nenavadna. Ta žival na splošno velja za nevarno in grozečo zver. Redko nastopa kot hvaležni ali spremljajoči volk: v daljni preteklosti ${ }^{24}$ ga srečamo pri Štivanu, na Bledu je znan pokop poznoantičnega volka iz 5 . - 6. stoletja, ${ }^{25} \mathrm{v}$ eni od zgodb o sv. Frančišku volka pri Gubbiju pokopljejo celo po krščansko, ${ }^{26}$ pod Snežnikom pa še skoraj sedaj volk sodeluje s človekom ${ }^{27}$. Zdi se, da volk v Lopichisovo zgodbo ni vključen s kakim namenom (hvaležnost, napad, obramba itd.), ampak se v kritičnem trenutku le kot senca prilepi beguncu,

24. Strabon; Marjeta Šašel Kos, “The story of the grateful wolf and Venetic horses in Strabo's Geography (Pripovedka o hvaležnem volku in venetskih konjih v Strabonovi Geografiji)", Studia mythologica Slavica, 11, 2008, 9-24.

25 Borut Toškan - Benjamin Štular, "Pes ali volk?: analiza kanidnega skeleta iz grobišča na Pristavi”, v: Andrej Pleterski (ur.), Zgodnjesrednjeveška naselbina na Blejski Pristavi, Opera Instituti archaeologici Sloveniae 14, Ljubljana 2008, 153, 156-157.

26 Zgodba je opisana pred letom 1390 v I Fioretti di San Francesco, Cap. 21. Že leta 1229 pa v pesmi "Legenda versificata" Henrik Abrincenški omenja volka, ki naj bi ga bil svetnik zlahka udomačil. Volk naj bi bil pokopan in pozneje naj bi bil v majhnem kamnitem sarkofagu našli okostje psa. Paolo Rossi, "Il lupo di Gubbio: storia o leggenda?", www.sanfrancesco.com/Ita/descrprodotto.asp?prod_id=372\&paese_ id $=20 \&$ destid $=73$ (koriščeno 28. 2. 2009).

27 Josip Potepan Škerljov, "Odgovor na pitanje družtva za Jugosl. poviest i starine”, Arkiv za porjestnicu jugoslavensku, 12, 1875, 256 (ponatis: Ivan Simčič - Franc Poklar - Tomo Šajn, Josip (Nadoslav) PotepanŠkrljov (1848-1893), Ilirska Bistrica 2008, 55). Primer bolj spominja na podomačen motiv iz zgodbe o Androklu in levu. 
ga spremlja in spodbuja k vztrajni hoji, a se takoj umakne, ko begunec nanj nameri lok... vendar se zdi, da je do tedaj že opravil svojo mentorsko nalogo. Begunca spremlja na poti iz ujetništva proti domovini: v Romuniji ${ }^{28}$ volk spremlja umrlega na oni svet, ${ }^{29} \mathrm{v}$ našem primeru pa iz sužnosti v svobodo. Ne v smrt in Had; ampak iz Hada ven in od smrti proč. Izjemni so dogodki v mitologiji, ko se posamezniki iz onstranstva vračajo na ta svet, s spremstvom ali brez spremstva, medtem ko večina senc ostane pri hudiču, kot tudi Lopichisovi preostali štirje bratje. Po pobegu Lopichis nekaj časa potuje z volkom, kateri mu kaže pot stran od ujetništva. In Lopichis do neke mere to vodstvo sprejema. A zaradi lakote je pripravljen volka vodnika ubiti. Se je vračal iz sužnosti kot volkodlak in se zaradi sosledja dogodkov počasi spreminjal v normalnega človeka, moškega? Dokončno vlogo je pri tem odigrala Slovanka, starejša ženska, ki ga je hranila postopoma, sicer bi lahko zaradi prenajedenosti umrl ("et secreto paulatim ei victum ministravit, ne, si ei usque ad saturitatem alimoniam praeberet, eius vitam funditus extingueret. Denique sic conpetenter ei pastum praebuit, quousque ipse recuperatus vires accipere potuisset”), oziroma se ne bi vrnil v domovino. Prav ta postopnost, tako pri hrani kot pri vrnitvi nasploh, govori za njegovo preobrazbo. Verjetno se z jesenovim drevesom ob vrnitvi domov preobrazba zaključi, in kot v pravljici si je povratnik uredil dom, izbral soprogo (in živel srečno do smrti), pa še za linijo potomcev je poskrbel.

Svojo zgodbo je Lopichis po povratku seveda pripovedoval v domačem okolju. Koliko je v njej langobardskih poganskih elementov, ne znamo oceniti. Upoštevamo pa dejstvo, da je odraščal v avarsko-slovanskem okolju pa so ob njem bile tudi ujete Langobardke iz prve generacije, ki so prišle v Italijo iz Panonije in so mu prispevale svoj del vzgoje in jezika. Vsekakor so v zgodbi elementi, za katere moramo iskati vzore pri vseh omenjenih etničnih skupinah pa še pri staroselcih od Panonije do Furlanije. Ne glede na izvor zgodbe je bila le-ta v domačem okolju sprejeta in se je ohranila skozi kar nekaj generacij. Zakaj in čemú? Ta hip moramo primerjati nekatere stereotipe, ki so se pozneje zelo razširili, a so bili očitno prisotni že v langobardskem okolju. V Lopichisovi zgodbi so skrite tri historične plemenske oznake: Avari, Slovani in Langobardi. Če Pavel Diakon ni bistveno posegal

28 Še v začetku 20. stoletja so v Romuniji peli pogrebno pesem "Il lupo apparirà davanti a te. Prendilo come tuo fratello, perché il lupo conosce l'ordine delle foreste. Egli ti condurrà per via piana verso il paradiso.", http://www.bibrax.org/europa_arcaica/mitologia/lupo.htm (koriščeno 7. 2. 2012).

29 Mirjam Mencej, "Volčji pastir v kontekstu dosedanjih raziskav na področju mitologije”, Studia mythologica Slavica, 4, 2001, 159-187. 
v njeno vsebino, so prav Langobardi Lopichisu iz izkušenj najmanj poznani, saj je odraščal med Avari in Slovani. Pač pa njegovo odločitev za beg lahko razumemo le ob upoštevanju domneve, da so ob njegovem odraščanju imele pomembno vlogo langobardske ženske, ki so nanj prenesle del predstav o Langobardih, o Italiji in o Furlaniji posebej. Med drugim verjetno tudi zgodbo o Romildi in predvsem o uspešnem begu mladega Grimoalda. Tako so ženske ${ }^{30}$, pa čeprav v čisto posebnem položaju - kot ujetnice v Panoniji - prevzele vlogo prenašalk plemenskega izročila. ${ }^{31}$ Njihov vpliv na mladega Lopichisa je moral biti globok, saj je tudi zategadelj znal med begom zaupati stari Slovanki. Končno je zgodbo prenesel na svojo družino v Čedadu. Kaj lahko je prav prenos izročila z ujetnic na Lopichisa pripomogel k opisu in zapisu Romildinega žalostnega konca in poboja Langobardov; mladoletni Lopichis je bil verjetno priča tega poboja med vračanjem zmagovalcev $\mathrm{z}$ ujetimi Langobardi v Panonijo, kar sicer ne spada v zgodbo o njegovem begu. Domnevamo, da je predvsem zgodba o dečku Grimoaldu, ki je kar dvakrat skušal pobegniti, ob tem pa je s svojo lepoto za hip omehčal Avara, konkretno vplivala na mladega Lopichisa in mu vsaj zasejala misel na beg. Seveda so bile poti za širjenje zgodb o usodi ujetnikov na poti proti Panoniji zelo priprte, saj se pokol ni dogodil še sredi langobardskega ozemlja, pač pa šele na vmesnem področju, tako da so bili priče o tem samo redki "takojšnji” begunci (Grimoald in njegovi bratje) ter langobardske ženske z Lopichisom in z ostalimi otroki. Ob povedanem ni težko sklepati, da je ad campum sacrum, kamor so z ujetniki prispeli zmagovalci na poti v Panonijo, treba locirati nekam na pot iz Čedada proti kraju, kjer je ujetništvo preživljal Lopichis, torej na povratno "alternativno pot” Ciglenečkega. Čeprav niso poznane osnove za lociranje ${ }^{32}$ "Svetega polja", lahko le domnevamo, da se je tradicija o odhajanju "beneandantov" na rodovitna polja okoli Cerkniškega jezera, Križne Gore in Snežnika ohranjala v Furlaniji vse do 16. stoletja, kot v zvezi s čarovništvom piše Catherine Carmichael. ${ }^{33}$ Dokazov za lokacijo "Campo santo" na tem področju pa nimamo.

30 Za vlogo žensk v zgodnjesrednjeveški družbi glej: Leslie Brubaker, Julia M. H. Smith (ed.), Gender in the early medieval world, Cambridge 2004.

31 Za ustno izročilo v zgodnjesrednjeveški družbi pa posebej Michael Richter (ed.), The oral tradition in the early middle ages, Brepols 1994.

32 Lokacijo Božje polje - Campo Sacro med Prosekom in Zgonikom na Krasu predvsem zaradi oddaljenosti od domnevne alternativne poti le težko upoštevamo. Podobno velja tudi za "Boxie pole" iz časa okoli 1400 pri Sv. Mihelu nad Borštom pri Trstu, torej tudi na Krasu. Vsekakor ostaja lociranje poboja Langobardov še odprto. 
Trditev, da je Lopichis bežal po alternativni poti, je mogoče podpreti ne le $\mathrm{z}$ navedbo naselja s slovansko govorico, ampak tudi z dogajanji v bližini. Znana je namreč omemba odkupovanja relikvij svetnikov in ujetnikov v Dalmaciji in Istri: tedaj, okoli let $640-642$, jih je opat Martin od poganov odkupoval tudi v Istri, kjer naj bi bili po domnevi M. Levaka tedaj že naseljeni Slovani. ${ }^{34}$ Naš vir torej posredno potrjuje Levakovo domnevo, kljub temu da na tem mestu predlagana Lopichisova pot poteka severneje od Snežnika, Brkinov in Čičarije, nekako ob robu dalmatinsko-istrskega področja, kjer naj bi bil dejaven opat Martin, hkrati pa tudi južneje od roba domnevno bolj strnjene poselitve Avarov, Slovanov in staroselcev na današnjem slovenskem ozemlju. Značilnost današnje pokrajine ob Lopichisovi poti sta goratost in pokritost z gozdovi in senožetmi (kot poudarja Gestrin za čas stalnih pregonov živine po 14. stoletju). Sliko (gozdnate) pokrajine lahko razberemo tudi iz Diakonovega teksta; to velja tudi za relevantna območja današnje Istrske in Primorsko-goranske županije.

$\mathrm{Na}$ prostoru Furlanije in vzhodno ležečih predelov lahko zaznamo dvoje akulturacij, ki se prepletata. Prva je romansko-langobardska v Furlaniji, ki je prisotna nekako od prehoda Langobardov iz Panonije v Italijo vse do 9. stoletja; druga pa je Lopichisova osebna, ki se je dogajala v njegovem ujetništvu: v začetku pod vplivom poboja ujetih moških in Romilde in pozneje pod vplivom ujetnic Langobardk, končala pa ob iniciaciji z volkom na begu, z odložitvijo loka na jesen in z osnovanjem družine v Čedadu. Obe akulturaciji sta povezani z lokom, plemensko zgodbo o volku in svetim jesenom, na katerega Lopichis obesi lok, in seveda z žensko-Slovanko, ki ob njeni skrbnosti preživi in se dokončno učloveči: volk ostane na kraških brezpotjih. Kronist Pavel Diakon je obe akulturaciji v pripovedi združil in sam nastopa $\mathrm{v}$ eni in $\mathrm{v}$ drugi.

* Zahvalo za sugestije sem dolžan gospej in gospodom: Vereni Vidrih Perko, Robertu Brusu, Jakovu Brdarju za razgovor o volkovih, Johnu Dillonu, Vladimirju Prozorovu, Stanku Flegu in Jožetu Hočevarju ter še posebej Samu Pahorju, Slavku Ciglenečkemu in Mauriziu Levaku.

34. Maurizio Levak, Slaveni vojvode Ivana: kolonizacija Slavena u Istri u početnom razdoblju franačke uprave, Zagreb 2007, 49-55. 


\section{Povzetek}

Avtor opisuje pobeg Langobarda Lopichisa iz avarsko-slovanskega ujetništva v prvi polovici 7. stoletja. Dogodek je opisal Pavel Diakon v drugi polovici 8. stoletja kot vrinek v kroniki Historia Langobardorum. Izražena je domneva, da so Langobardi že leta 568 na poti v Italijo uporabili "alternativno" pot po dolini Krke čez Dolenjsko in Notranjsko v Sloveniji in vsekakor južno od Save. Približno isto pot omenja Strabon še v halštatskodobnem kontekstu (Okra - kompleks Stične ali pa Novo mesto). Ta smer je bila uporabljena, po F. Gestrinu, tudi v poznem srednjem veku za gonjenje živine iz Panonije proti Trstu. Že omenjenim domnevam se pridružuje tudi ta, da so Avari s Slovani odvedli l. 610 ujete Langobarde po isti poti iz Čedada proti Panoniji, konkretno proti Sisku.

Avtor posebej poudarja dogodke, povezane z odraščajočim Lopichisom: bivanje $\mathrm{v}$ ujetništvu, skupaj s preživelimi Langobardkami, tradicijo o domovini v Furlaniji, stike Lopichisa z gospodarji in obvladovanje slovanščine, odločitev za beg in lok s puščicami, hojo po redko naseljeni pokrajini. Poudari srečanje z volkom, ki je prevzel vodenje vse dotlej, ko se je Lopichis odločil ustreliti ga z lokom, ki ga je obdržal vse do prihoda v domovino (Čedad). Poskuša interpretirati tudi srečanje v snu z moško postavo, ki mladeniču ukaže, naj nadaljuje pot, kot mu kažejo noge. Pomenljivo je srečanje s staro žensko v naselju, kjer se je govorilo slovansko. Starka ga je skrivoma negovala in ga končno napotila dalje proti zahodu. Kot zrel moški se vrne domov, najde rojstno hišo, drevo in tudi soprogo. Njegov pravnuk je Pavel Diakon, pisec Historie Langobardorum.

Avtor tudi omeni, da se je Lopichis gibal sicer severno od roba dalmatinsko-istrskega področja, koder je bil okoli 640-642 dejaven opat Martin, hkrati pa tudi južneje od roba domnevno bolj strnjene poselitve Avarov, Slovanov in staroselcev na današnjem slovenskem ozemlju. Dejavnost opata Martina v Istri M. Levak interpretira kot posredno potrditev zgodnje naselitve Slovanov v Istro, podobno pa avtor to naselitev nakazuje z lokacijo in datacijo srečanja Lopichisa s starko, ki je živela v naselju (kjer se je govorilo slovansko), sicer nekje ob severnem robu Istre.

\section{Čovjek vuku vuk (o odnosima čovjeka i vuka u Historia Langobardorum Pavla Đakona) \\ Sažetak}

Autor razmatra bijeg Langobarda Lopihisa iz avarsko-slavenskoga zarobljeništva u prvoj polovici 7. stoljeća. Događaj je opisao Pavao Đakon u drugoj polovici 8. stoljeća kao umetak u kronici Povijest Langobarda. Iznesena je pretpostavka da su se Langobardi već 568. godine na putu u Italiju koristili "alternativnim" putom dolinom rijeke Krke kroz Dolenjsku i Notranjsku u Sloveniji i svakako južno od Save. Približno isti put spominje Strabon još u halštatskodobnom kontekstu (Okra - kompleks Stične ili pak Novo mesto). Taj je pravac bio korišten, po F. Gestrinu, i u kasnom srednjem vijeku za gonjenje stoke iz Panonije prema Trstu. Već spomenutim pretpostavkama pridružena je i ta da su 610. Avari sa Slavenima odveli zarobljene Langobarde istim putem iz Čedada prema Panoniji, točnije prema Sisku. 
Autor posebno ističe događaje povezane s odrastajućim Lopihisom: boravak u zatočeništvu, zajedno s preživjelim Langobartkama, tradiciju o domovini u Furlaniji, Lopihisove kontakte s gospodarima i svladavanje slavenskoga jezika, odlučivanje na bijeg i luk sa strijelama, pješačenje po rijetko naseljenom području. Naglašava susret s vukom, koji je preuzeo vodstvo sve dotle dok ga Lopihis nije odlučio ustrijeliti lukom koji je sačuvao do povratka u domovinu (Čedad). Pokušava interpretirati i susret u snu s muškim likom koji je mladiću zapovjedio da nastavi putom na koji mu noge ukazuju. Značajan je susret sa starom ženom u naselju u kojemu se govorilo slavenskim jezikom. Starica ga je krišom njegovala i na koncu uputila dalje prema zapadu. Vraća se kao zreo muškarac, nalazi rodnu kuću, stablo i suprugu. Njegov je praunuk Pavao Đakon, pisac Povijesti Langobarda.

Autor također napominje da se Lopihis inače kretao sjeverno od ruba dalmatinsko-istarskoga područja, gdje je oko 640. - 642. djelovao opat Martin, a ujedno i južno od ruba pretpostavljene gušće naseljenosti Avara, Slavena i starosjedilaca na današnjem slovenskom ozemlju. Djelovanje opata Martina u Istri M. Levak interpretira kao posrednu potvrdu ranoga naseljavanja Slavena u Istru. U skladu s tim autor na to naseljavanje ukazuje lokacijom i datacijom Lopihisova susreta sa staricom koja je živjela u naselju (u kojemu se je govorilo slavenski) negdje na sjevernom rubu Istre.

\section{Man is wolf to wolf (about the man-wolf relationship in Historia Langobardorum by Paul the Deacon)}

\section{Summary}

The author is exploring the escape of Lopichis, a Langobard, from the Avaro-Slavic captivity in the first half of the $7^{\text {th }}$ century. The escape was described by Paul the Deacon in the second half of the $8^{\text {th }}$ century as an insertion in the Historia Langobardorum chronicle. An assumption was made that the Langobards have used an alternative route to Italy in 568 through the valley of Krka river, through Dolenjska and Notranjska in Slovenia and definitely the route south of the Sava river. The same road is mentioned by Strabo in the context of the Hallstatt age (Okra-Stična complex or Novo mesto). According to F. Gestrin, this road was used in the late medieval period for cattle from Pannonia to Trieste. There was another assumption; that in 610 the Avars took the enslaved Langobards with the Slavs using the same route from Cividale to Pannonia, i. e. Sisak.

The author's emphasis is on young Lopichis: his captivity with the surviving Langobard women, tradition in his homeland Friuli, his contacts to his masters and learning the Slavic language, deciding to run away and his bow and arrows, walking the poorly inhabited lands. He mentions the encounter with a wolf who took the leadership until Lopichis decided to shoot him with a bow he saved until he returned to his homeland (Cividale). The author is trying to interpret a dream in which a man commanded the boy to continue the route by which his legs are taking him. A meaningful encounter happened with an old woman in a village who spoke the Slavic language. The old woman nurtured him to health in secret 
and sent him to the west. He returns as a man, finds the house he was born in, tree, his wife. His grandson is Paul the Deacon, writer of Historia Langobardorum.

The author mentioned that Lopichis was heading north of the edge of the Dalmatia - Istria territory during the same period as Abbot Martin, 640 - 642, and south of the area where there were more Avars, Slavs and aborigines in today's Slovenian lands. The presence and work of Abbot Martin in Istria is interpreted by M. Levak as an affirmation of arrival of Slavs in Istria. The author elaborates this arrival with the locations and dating of Lopichis' meeting with the old woman who lived in the village (where Slavic language was spoken) somewhere on the northern edge of Istria.

\section{Priloge}

\section{P. Diaconus, Historia Langobardorum, IV, 37:}

Circa haec tempora rex Avarum, quem sua lingua Cacanum appellant, cum innumerabili multitudine veniens, Venetiarum fines ingressus est. Huic Gisulfus Foroiulanus dux cum Langobardis, quos habere poterat, audacter occurrit; sed quamvis forti animositate contra inmensam multitudinem bellum cum paucis gereret, undique tamen circumseptus, cum omnibus pne suis extinctus est. Uxor vero eiusdem Gisulfi nomine Romilda cum Langobardis qui evaserant sive eorum uxoribus et filiis qui in bello perierant, intra murorum Foroiulani castri [se] muniit septa. Huic erant filii Taso et Cacco iam adulescentes, Raduald vero et Grimuald adhuc in puerili aetate constituti. Habebat vero et filias quattuor, quarum una Appa, alia Gaila vocabatur, duarum vero nomina non retinemus. Communierant se quoque Langobardi et in reliquis castris quae his vicina erant, hoc est in Cormones, Nemas, Osopo, Artenia, Reunia, Glemona, vel etiam in Ibligine, cuius positio omnino inexpugnabilis existit. Pari etiam modo et in reliquis castellis, ne Hunnis, hoc est Avaribus, praeda fierent, se communivere. Avares vero per omnes Foroiulanorum fines discurrentes, omnia incendiis et rapinis vastantes, Foroiulanum oppidum obsidione claudunt et totis viribus expugnare moliuntur. Horum rex, id est Cacanus, dum circa muros armatus cum magno equitatu perambularet, ut, qua ex parte urbem facilius expugnare posset, inquireret, hunc Romilda de muris prospiciens... (...) Exigit vero nunc locus, postposita generali historia, pauca etiam privatim de mea, qui haec scribo, genealogia retexere, et quia res ita postulat, paulo superius narrationis ordinem replicare. Eo denique tempore quo Langobardorum gens de Pannoniis ad Italiam venit, Leupchis meus abavus ex eodem Langobardorum genere cum eis pariter adventavit. Qui postquam aliquot annos in Italia vixit, diem claudens extremum, quinque ex se genitos filios adhuc parvulos reliquit; quos tempestas ista captivitatis, de qua nunc diximus, conprehendens, omnes ex castro Foroiulensi in Avarorum patriam exules deduxit. Qui cum per multos annos in eadem regione captivitatis miseriam sustinuissent et iam ad virilem pervenissent aetatem, ceteris quattuor, quorum nomina non retinemus, in captivitatis angustia persistentibus, quintus eorum germanus nomine Lopic- 
his, qui noster postea proavus extitit, inspirante sibi, ut credimus, misericordiae auctore, captivitatis iugum abicere statuit et ad Italiam, quo gentem Langobardorum residere meminerat, tendere atque ad libertatis iura studuit reppedare. Qui cum adgressus fugam adripuisset, faretram tantum et arcum et aliquantulum cibi propter viaticum gerens, nesciretque omnino quo pergeret, ei lupus adveniens comes itineris et ductor effectus est. Qui cum ante eum pergeret et frequenter post se respiceret et cum stante subsisteret atque cum pergente praeiret, intellexit, sibi eum divinitus datum esse, ut ei iter, quod nesciebat, ostenderet. Cum per aliquot dies per montium solitudines hoc modo pergerent, panis eidem viatori, quem exiguum habuerat, omnino defecit. Qui cum ieiunans iter carperet et iam fame tabefactus defecisset, tetendit arcum suum et eundem lupum, ut eum in cibum sumere possit, sagitta interficere voluit. Sed lupus idem ictum ferientis praecavens, sic ab eius visione elapsus est. Ipse autem, recedente eodem lupo, nesciens quo pergeret, insuper famis penuria nimium debilis effectus, cum iam de vita desperaret, sese in terram proiciens, obdormivit; viditque quendam virum in somnis talia sibi verba dicentem: "Surge! Quid dormis? Arripe viam in hanc partem contra quam pedes tenes; illac etenim est Italia, ad quam tendis". Qui statim surgens, in illam partem quam in somnis audierat pergere coepit; nec mora, ad habitaculum hominum pervenit. Erat enim Sclavorum habitatio in illis locis. Quem cum una mulier iam vetula vidisset, statim intellexit, eum fugitivum esse et famis penuria laborare. Ducta autem misericordia super eum, abscondit eum in domo sua et secreto paulatim ei victum ministravit, ne, si ei usque ad saturitatem alimoniam praeberet, eius vitam funditus extingueret. Denique sic conpetenter ei pastum praebuit, quousque ipse recuperatus vires accipere potuisset. Cumque eum iam validum ad iter faciendum vidisset, datis ei cibariis, ad quam partem tendere deberet, admonuit. Qui post aliquot dies Italiam ingressus, ad domum in qua ortus fuerat pervenit; quae ita deserta erat, ut non solum tectum non haberet, sed etiam rubis et sentibus plena esset. Quibus ille succisis intra eosdem parietes vastam hornum repperiens, in ea suam faretram suspendit. Qui postea consanguineorum et amicorum suorum muneribus dotatus, et domum reaedificavit et uxorem duxit; sed nihil de rebus quas genitor suus habuerat, exclusus iam ab his qui eas invaserant longa et diuturna possessione, conquirere potuit. Iste, ut iam superius praemisi, extitit meus proavus. Hic etenim genuit avum meum Arichis, Arichis vero patrem meum Warnefrit, Warnefrit autem ex Theudelinda coniuge genuit me Paulum meumque germanum Arichis, qui nostrum avum cognomine retulit. Haec paucis de propriae genealogiae serie delibatis, nunc generalis historiae revertamur ad tramitem. 


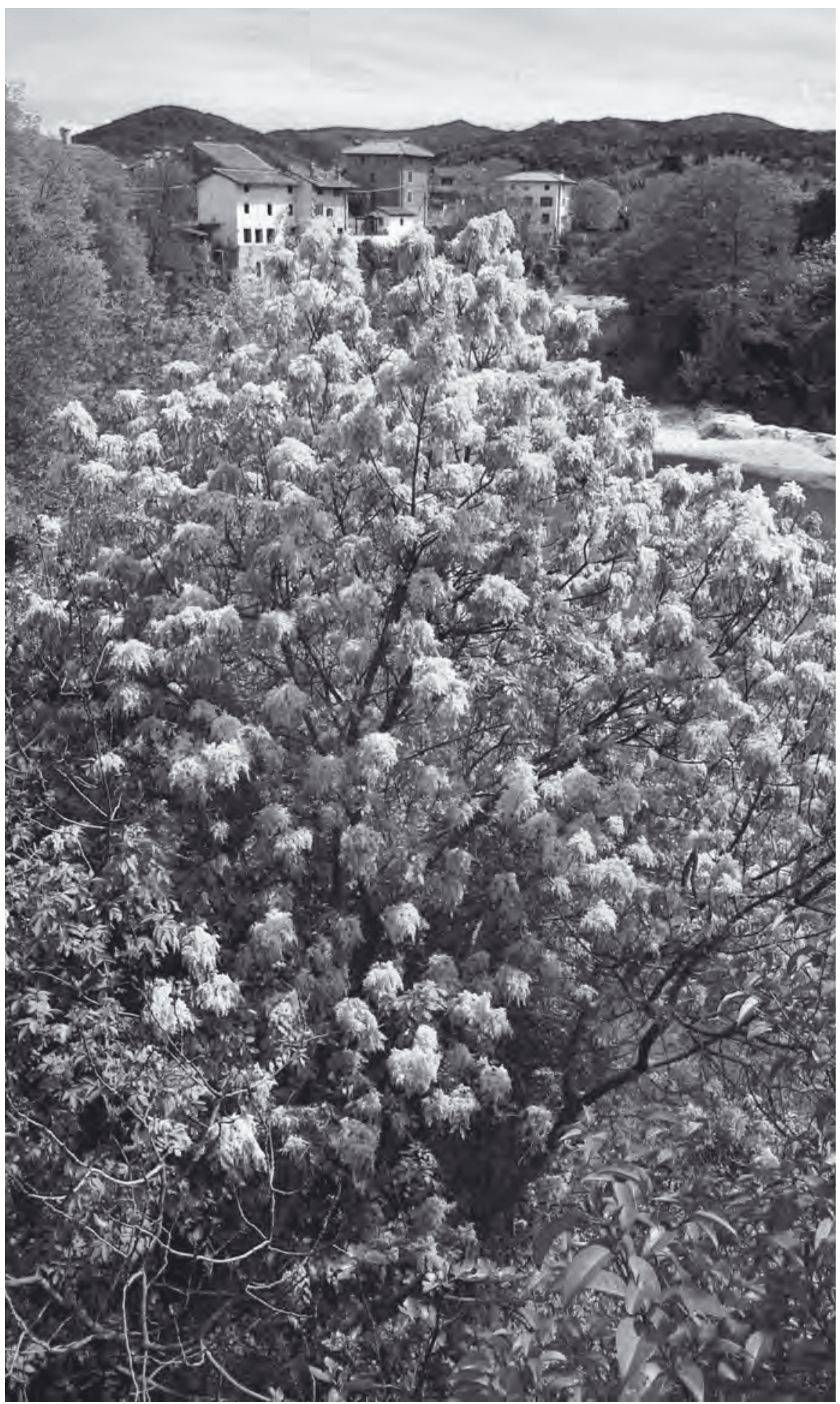

Sl. 1. Fraxinus hornus (mali jesen), Čedad. Fotografija: R. Brus. 
